\title{
A SÍLABA: UMA BREVE REVISÃO
}

Taíse Simioni*

RESUMO: O presente texto tem por objetivo realizar uma revisão sobre a sílaba como um constituinte prosódico. Para tal, optamos por trazer noções básicas envolvidas em qualquer discussão sobre a sílaba: a estrutura deste constituinte prosódico, sua formação, ou seja, como as palavras são escandidas em sílabas, e os argumentos favoráveis à sua existência como um constituinte prosódico. Sobre a estrutura da sílaba, trazemos propostas teóricas que divergem sobre a existência de constituintes subsilábicos. A respeito da formação da sílaba, discutimos brevemente sobre os templates, as restrições colocacionais e o princípio de maximização do ataque, tomando como referência, principalmente, o português brasileiro. Por fim, trazemos argumentos que mostram a necessidade da sílaba como um constituinte prosódico.

PALAVRAS-CHAVE: Sílaba - Constituintes silábicos - Teoria

ABSTRACT: This text aims to make a review of the syllable as a prosodic constituent. For this task, we chose to raise basic notions involved in any discussion on the syllable: the structure of this prosodic constituent, its formation, that is, how words are divided into syllables, and the arguments that favor its existence as a prosodic constituent. Concerning the structure of the syllable, we comment on theoretical proposals that diverge about the existence of subsyllabic constituents. As for the formation of the syllable, we briefly discuss the templates, the collocational restrictions and the Maximal Syllable Onset Principle, mainly in reference to Brazilian Portuguese. At last, we bring arguments showing the necessity of the syllable as a prosodic constituent.

KEYWORDS: Syllable - Syllabic Constituents - Theoretical review

\section{INTRODUÇÃO}

Este texto tem por objetivo fazer uma breve revisão a respeito do menor constituinte prosódico: a sílaba. Para isso, começamos por confrontar duas propostas teóricas de análise da estrutura da sílaba: a proposta autossegmental, segundo a qual a sílaba não possui estrutura interna, e a abordagem métrica, que defende a existência de uma estrutura interna para a sílaba. Limitamo-nos a apresentar tais propostas; não temos, portanto, o objetivo de defender qualquer uma delas. Isso não nos impede, entretanto, de mostrar possíveis problemas enfrentados por estas propostas. Na seqüência, discutimos como uma palavra é escandida em sílabas, mostrando os mecanismos formais que regulam tal escansão. Nesta seção, apresentamos os templates, as restrições colocacionais e o princípio de maximização do ataque. Para finalizar, trazemos argumentos que justificam a existência da sílaba como um constituinte prosódico.

\footnotetext{
Doutoranda em Letras da Universidade Federal do Rio Grande do Sul. E-mail: taisesimioni@yahoo.com.br.
} 


\section{A ESTRUTURA DA SÍLABA}

Partindo da idéia de que a sílaba é um constituinte prosódico, diferentes propostas procuraram dar conta do modo como este constituinte se organiza. Discorreremos, aqui, sobre a proposta autossegmental e a abordagem métrica.

Apesar de as propostas compartilharem o pressuposto de que a sílaba é uma unidade de análise fonológica (pressuposto cuja justificativa será apresentada adiante), a análise autossegmental e a abordagem métrica distinguem-se, basicamente, pelo fato de que a primeira não admite que a sílaba tenha estrutura interna, enquanto a segunda prevê que a sílaba seja dividida em unidades menores, embora, como veremos, não haja consenso sobre tal estrutura interna.

Falemos, então, sobre a proposta autossegmental. De acordo com essa análise, formulada por Kahn (1976) e adotada, entre outros autores, por Itô (1986) e Nespor e Vogel (1986), os segmentos encontram-se ligados diretamente ao nó silábico, como vemos em (1). Na verdade, a estrutura silábica adotada por Itô (1986) prevê que entre o nó silábico e os segmentos, que compõem a camada melódica, há a camada esqueletal (2), responsável por distinções qualitativas no interior da sílaba, no sentido de que essa camada é capaz de distinguir uma vogal longa de uma breve (a primeira apresentará dois Vs na camada esqueletal e apenas um segmento na camada melódica) e uma consoante geminada de uma consoante simples (a primeira apresentará dois Cs na camada esqueletal e apenas um segmento na camada melódica). A camada esqueletal, entretanto, não representa uma organização interna da sílaba. Trata-se de um nível quantitativo (porque é capaz de fazer distinções entre vogais longas e breves, por um lado, e entre consoantes geminadas e simples, por outro lado), em oposição a um nível qualitativo, que é o da camada melódica, onde se encontram os segmentos.

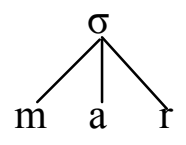

(2)

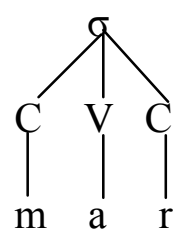

Segundo a abordagem métrica, entretanto, entre os segmentos e o nó silábico, há outros constituintes, como ataque e rima, conforme podemos observar em (3). Para esta proposta, portanto, a sílaba apresenta uma estrutura interna. Entre os autores que defendem essa análise, estão Selkirk (1982) e Harris (1983). 
(3)<smiles>[3H][R]([Tl])=C[TlH]</smiles>

O pressuposto de que a sílaba possui estrutura interna apóia-se no fato de que parece haver uma relação mais estreita entre os segmentos que compõem a rima do que entre estes e os segmentos que constituem o ataque.

Selkirk (1982) e Harris (1983) analisam a estrutura da rima de maneiras diferentes. Para Selkirk, a rima apresenta uma divisão entre núcleo e coda (4), enquanto Harris afirma que não há evidências para esta divisão. Conforme a proposta do autor, em uma rima com mais de dois segmentos, como na primeira sílaba de perspectiva, a rima cria uma estrutura recursiva, pois, segundo Harris, os constituintes silábicos são binários (5).

(4)

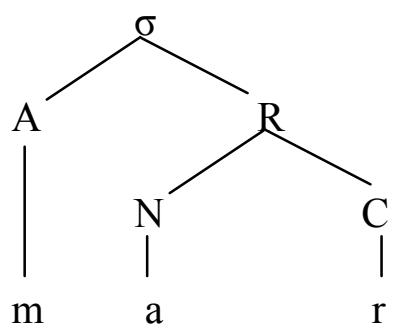

(5)

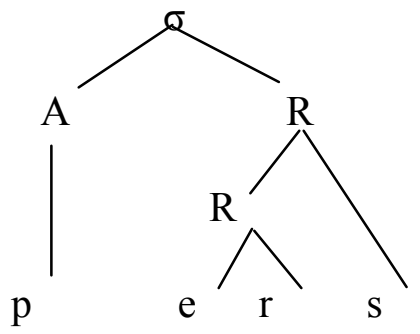

Harris (1983) analisa vários processos fonológicos que, segundo o autor, poderiam ser mais bem explicados se a noção de constituintes subsilábicos fosse introduzida na formulação de suas regras. Um exemplo é o processo de velarização que ocorre no espanhol: um segmento nasal realiza-se como velar quando em posição de rima (cantan $\rightarrow c a[\mathrm{y}] \operatorname{ta}[\mathrm{y}]$ 'cantam'). Harris (1983, p. 47) formaliza a regra da seguinte maneira:

(6)<smiles>[R][Tl][10BH2]</smiles> 
Segundo o autor, portanto, esse processo traz evidências para a existência da rima como um constituinte subsilábico. Nespor e Vogel (1986), entretanto, afirmam que as mesmas regras utilizadas por Harris para justificar a rima e, portanto, a divisão interna da sílaba podem ser reformuladas de maneira a só fazer menção à sílaba. Nespor e Vogel (1986, p. 75) formulam a regra de velarização, por exemplo, da maneira como vemos em (7). Segundo essa regra, uma nasal se realizará como velar quando estiver em final de sílaba e for sucedida ou não por uma ou mais consoante, como em constante $\rightarrow$ co[y]sta[y]te 'constante'.

$$
\left.\mathrm{n} \rightarrow \mathrm{y} / \mathrm{C}_{0}\right]_{\sigma}
$$

Há, portanto, argumentos favoráveis tanto a uma quanto a outra proposta. Entretanto, quando se considera o acento, segundo Nespor e Vogel (1986), parece haver a necessidade de uma divisão interna à sílaba, tendo em vista que, em línguas sensíveis ao peso silábico, uma rima ramificada contribui para o peso, mas um ataque ramificado não. Cabe mencionar que uma rima ramificada pode ser constituída por um núcleo seguido de uma coda ou por um núcleo ramificado.

\section{A ESCANSÃO DE UMA PALAVRA EM SÍLABAS}

\section{Os templates e as restrições colocacionais}

Segundo Selkirk (1982, p. 344), a função de um template é representar as características gerais das sílabas em uma dada língua. Para a autora, a boa formação de uma sílaba será regulada pela sua conformação em relação ao template de uma língua. O template sugerido por Bisol (1999, p. 703) para o português encontra-se em (8). Os parênteses indicam constituintes não-obrigatórios. Podemos ver que, em português, o único constituinte obrigatório é o núcleo, que, nessa língua, só pode ser preenchido por vogal; há, portanto, sílabas formadas apenas por uma vogal, como a primeira sílaba de abraço.

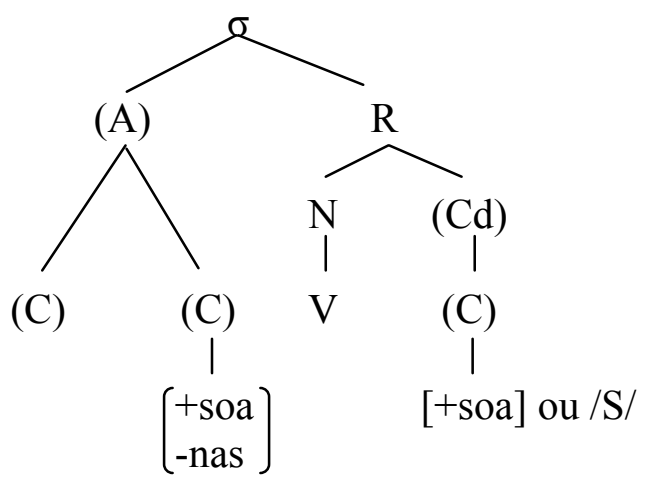

Esse template (i) gera as sílabas bem formadas em português: é, pá, preto, az, bosque, flor; (ii) exclui algumas sílabas malformadas: *tpa, *bap; (iii) mas não é capaz 
de excluir outras sílabas malformadas: aquelas com ataque complexo cujo primeiro segmento é uma fricativa não-labial, como *sla, *zra, *xla, etc. Para excluir essas sílabas, são necessárias restrições colocacionais. Bisol $(1999$, p. 718$)$ propõe a condição positiva do ataque complexo para desempenhar essa função (9).

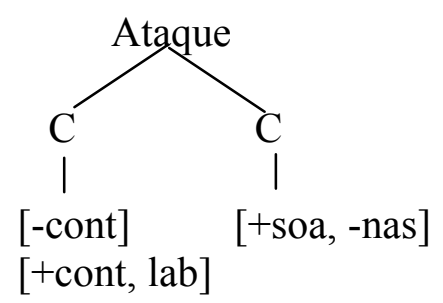

Para que uma sílaba seja bem formada em português, portanto, ela deve respeitar o template em (8) e a restrição em (9). Para finalizar, é necessário explicar as sílabas em palavras como monstro, claustro e perspectiva. As sílabas destacadas, apesar de serem bem formadas, apresentam codas que não se conformam ao template em (8). Para dar conta disso, Bisol (1999, p. 704) propõe para o português a regra de adjunção de $/ S /$, segundo a qual um $/ \mathrm{S} /$ pode ser acrescentado a uma rima bem formada.

\section{O princípio de maximização do ataque}

Muitos autores fazem menção, de maneira mais ou menos direta, ao princípio de maximização do ataque. Segundo esse princípio, consoantes intervocálicas serão silabificadas maximamente como ataque de uma sílaba, isto é, uma seqüência VCV será silabificada como V.CV e não como VC.V. Tal princípio é orientado pelo pressuposto de que uma sílaba deve ter um aumento máximo de sonoridade no ataque e uma queda mínima de sonoridade na rima (cf. Clements, 1990, embora o autor não divida as sílabas em ataque e rima, mas em demissílabas). Uma sílaba $\mathrm{CV}$ permite esse padrão, ao contrário de uma sílaba VC.

Selkirk (1982, p. 358) mostra que uma palavra como allow 'permitir' do inglês

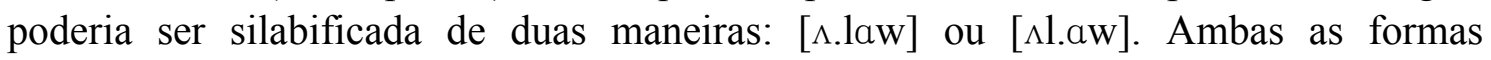
respeitam o molde silábico e as regras colocacionais do inglês, que não discutiremos aqui. Além disso, nenhuma delas viola o princípio de sonoridade seqüencial, segundo o qual a sonoridade deve aumentar das margens em direção ao núcleo de uma sílaba. Apesar disso, somente [ $\Lambda$. law] é permitido, em função de que essa forma respeita o princípio de maximização do ataque. Bisol (1999, p. 712) mostra que, em português, uma palavra como ala será silabificada como [a.la], e não [al.a], também em função desse princípio.

Há situações, entretanto, em que outros fatores farão com que uma consoante intervocálica não seja silabificada como ataque de uma sílaba, ao contrário do que seria predizível pelo princípio de maximização do ataque. Quando fronteiras morfológicas estão envolvidas na silabificação, podemos encontrar casos em que um limite de morfema pode corresponder a um limite de sílaba. Booij (1996) traz o exemplo da palavra holandesa verassen 'incinerar', constituída pelo prefixo [ver] e pela raiz [as]. Segundo os autores, essa palavra é silabificada como [ver.as], e não como *[ve.ras], conforme seria esperado pelo princípio de maximização do ataque. Não nos deteremos 
nessa análise aqui, mas a explicação para essa escansão em sílabas encontra-se em questões como o status prosódico de morfemas como afixos e o domínio de silabificação, que varia de língua para língua (cf. Nespor e Vogel, 1986, p. 63-64).

\section{JUSTIFICATIVAS PARA A EXISTÊNCIA DA SÍLABA COMO UM CONSTITUINTE PROSÓDICO}

A sílaba não tem correlatos fonéticos claramente definidos. Segundo Kentowicz (1994), esse foi um dos motivos para que esse constituinte tenha sido negligenciado no início dos estudos gerativos. Entretanto, conforme Kentowicz (1994, p. 250), trata-se de "uma unidade essencial de organização prosódica". O autor justifica essa afirmação através de três argumentos: (i) a sílaba é domínio de restrições fonotáticas, (ii) regras fonológicas podem ser mais bem expressas se fizerem referência à sílaba e (iii) vários processos fonológicos são mais bem entendidos se forem concebidos como maneiras de tornar os segmentos possíveis de serem escandidos em sílabas.

Vejamos exemplos em português para os três argumentos. O primeiro diz que a sílaba é domínio de restrições fonotáticas. Em português, uma seqüência como st é proibida se ela for tautossilábica $\left({ }^{*} s t a, * a t s\right)$, mas não se for heterossilábica (pasta). Essa diferença só pode ser expressa através da referência à sílaba, ou seja, por meio dos templates silábicos e das restrições colocacionais. Palavras bem formadas serão aquelas cujas sílabas são bem formadas ${ }^{1}$.

Com relação ao segundo argumento, algumas regras fonológicas têm como domínio a sílaba. Em português, a regra de vocalização da lateral (falta $\rightarrow f a[\mathrm{w}] t a$ ) aplica-se quando a lateral encontra-se no fim de uma sílaba. Sem referência à sílaba, essa regra teria de ser formalizada como em (10). Segundo esta regra, a lateral é vocalizada quando estiver diante de outra consoante ou quando estiver em final de palavra.

$$
1 \rightarrow \mathrm{w} /\left[\begin{array}{l}
\mathrm{C} \\
\#
\end{array}\right\}
$$

Como afirma Kahn (1976), com relação a uma regra do inglês, o contexto dessa regra tem problemas porque consoantes e final de palavra não formam uma classe natural. Em termos silábicos, a regra em (10) pode ser refeita como (11), em que a estrutura interna da sílaba é considerada, ou como (12), em que não há referência a essa estrutura interna.

$$
1 \rightarrow \mathrm{w}
$$

\footnotetext{
${ }^{1}$ Há algumas restrições fonotáticas que fazem referência à palavra. Em português, por exemplo, [n] e $[\kappa]$
} palavra, como atesta a epêntese inicial em palavras iniciadas por esses segmentos (nhoque, lhama). 


$$
1 \rightarrow \mathrm{w} /[]_{\sigma}
$$

Por fim, com relação ao terceiro argumento, o processo de epêntese é bastante esclarecedor. Em palavras como pacto e apnéia, uma vogal é inserida (pa[ki]to, $a$ [pi]néia). Essa inserção se justifica porque as consoantes [k] e [p], respectivamente, não podem ser silabificadas nem como coda da sílaba anterior nem como ataque complexo da sílaba seguinte e não podem, tampouco, constituir um núcleo silábico. Essas consoantes, então, podem ser caracterizadas como segmentos "perdidos". Como vimos acima, isso se deve ao template descrito em (8). Por stray erasure, um segmento não-silabificado é apagado. No caso do português, a vogal epentética é inserida para que a consoante perdida possa ser silabificada, evitando, portanto, seu apagamento. Outra opção para que um segmento não-silabificado não seja apagado é a extrassilabicidade. As consoantes em questão, entretanto, não podem ser salvas por ela tendo em vista que se admitem segmentos extrassilábicos somente nas margens de uma palavra, o que não é o caso dos dados que analisamos.

Através desses argumentos, então, justifica-se a existência da sílaba como um constituinte prosódico.

\section{REFERÊNCIAS}

BISOL, Leda. A sílaba e seus constituintes. In: NEVES, Maria Helena de Moura (org.). Gramática do português falado. v. 7: Novos Estudos. Campinas: Ed. da UNICAMP, 1999, p. 701-742.

BOOIJ, Geert. Cliticization as prosodic integration: the case of Dutch. The linguistic review, 13, p. 219-242, 1996.

CLEMENTS, George N. The role of the sonority cycle in core syllabification. In: KINGSTON, J.; BECKMAN, M. (orgs.). Papers in laboratory phonology 1. Cambridge, CUP: 1990, p. 283-333.

HARRIS, James. Syllable structure and stress in Spanish. 1983. Tese (Doutorado, PhD) - Cambridge, Mass.: MIT.

ITÔ, Junko. Syllable theory in prosodic phonology. 1986. Tese (Doutorado, PhD) University of Massachussetts.

KAHN, Daniel. Syllable - based generalizations in English phonology. 1976. Tese (Doutorado, PhD) - Cambridge, Mass: MIT.

KENSTOWICZ, Michael. Phonology in generative grammar. London: Basil Blackwell, 1994.

NESPOR, Marina; VOGEL, Irene. Prosodic phonology. Dordrecht-Holland: Foris Publications, 1986.

SELKIRK, Elisabeth. The syllable. In: HULST, H.; SMITH, Van Der. The structure of phonological representations (part. II). Dordrecht-Holland: Foris Publications, 1982, p. 337-383. 